ISSN 2077-1827. Гуманізація навчально-виховного процесу. 2020, №. 1 (99)

РОЗДІЛ. ДОШКІЛЬНЕ ВИХОВАННЯ

УДК 373.2(015.31:793.4/7)

\title{
ШЕБЕКО Валентина
}

доктор пед. наук, доцент, профессор кафедры методик дошкольного образования учреждения образования «Белорусский государственный педагогический университет имени Максима Танка»

ул. Советская 18, Минск, Беларусь, 220050,

E-mail: walj-schebeko@,mail.ru

\section{ГО Кэ}

аспирант кафедры методик дошкольного образования учреждения образования «Белорусский государственный педагогический университет имени Максима Танка»

ул. Советская 18, Минск, Беларусь, 220050,

E-mail: 302900817@qq.com

\section{ЭМОЦИОНАЛЬНОЕ БЛАГОПОЛУЧИЕ ДЕТЕЙ СТАРШЕГО ДОШКОЛЬНОГО ВОЗРАСТА, ПРОБЛЕМА ЕГО ИЗУЧЕНИЯ И ФОРМИРОВАНИЯ}

Резюме. В статье представлен аналитический обзор теоретических подходов к проблеме эмоционального благополучия детей. Отмечается, что понятие «эмоциональное благополучие» приобрело самостоятельный статус, дифференцируюсь от более общих понятий «психическое здоровье», «психологическое здоровье», «психологическое благополучие». Внимание исследователей привлекает изучение поведенческих и эмоциональных состояний детей, функций, выполняемых ими. В настоящее время выделяется новое направление в исследовании эмоционального благополучия детей, где оно рассматривается как синоним понятия «эмоциональное здоровье», критериями которого выступают: наличие целостного эмоционального отношения ребенка к себе и к миру; способность трансформировать отрицательные эмоции и вызывать положительно окрашенные переживания; включенность во взаимодействие с социальной средой; способность к саморегуляции и творческому освоению способов, нарушающих эмоциональное благополучие. Несмотря на разность подходов в определении эмоционального благополучия исследователи различных специальностей пришли к выводу, что оно представляет собой многомерное явление, которое определяет эмоциональное самочувствие ребенка, является показателем успешности его эмоциональной регуляции и неразрывно связано с его психологическим здоровьем.

Целью исследования явилось опытно-экспериментальное изучение эмоционального благополучия детей старшего дошкольного возраста, выявление как положительных, так и отрицательных сторон изучаемой проблемы; определение содержания педагогической деятельности, направленной на формирование у воспитанников позитивных эмоций, позитивного отношения к себе в процессе выполнения физических упражнений.

Приводятся данные эмпирического исследования состояния эмоционального благополучия детей старшего дошкольного возраста. Результаты итогового анализа материалов диагностических методик позволили СШебеко В., Го К., 2020 
ISSN 2077-1827. Гуманізація навчально-виховного процесу. 2020, №. 1 (99)

РОЗДІЛ. ДОШКІЛЬНЕ ВИХОВАННЯ

констатировать, что степень проявления основных признаков эмоционального благополучия детей контрольных и экспериментальных групп зафиксирована как недостаточная. В формирующей части эксперимента использовались формы и методы работы, обеспечивающие навыки эмоционального самовыражения ребенка в двигательной деятельности, влияющие на осознание им своих чувств, переживаний и эмоциональных состояний. Главным условием реализации поставленной цели выступала игра.

Исследованием доказано, что в игре, с одной стороны, обнаруживаются уже сложившиеся у детей способы и привычки эмоционального реагирования, с другой, - формируются новые качества поведения, развивается и обогащается эмоциональный опыт. Особо значим в игре момент перевоплощения в игровой образ, он выступает важнейшим условием перестройки и оптимизации эмоциональной сферы детей. Таким образом, игровая форма организации двигательной деятельности, обеспечивающей преобладание положительных эмоций, понимание ребенком характера переживаемых эмоций, приобретение эмоционально положительного опыта общения со сверстниками может явиться действенным фактором формирования эмоционального благополучия детей.

Ключевые слова: психологическое здоровье, эмоциональное благополучие, эмоциональное развитие, положительный фон настроения, двигательная деятельность, игра, двигательные инсценировки, музыкальноритмические упражнения.

Постановка проблемы в общем виде и ее связь с важными научными или практическими заданиями. Актуальность проблемы эмоционального благополучия детей дошкольного возраста определяется социальным заказом общества на воспитание здорового ребенка, поэтому дошкольный период детства должен быть пронизан заботой о физическом здоровье и психическом благополучии воспитанников. Как показатель оптимальности общего психического развития рассматривается эмоциональное благополучие детей, определяющее позитивное отношение ребёнка к миру и к самому себе, обеспечивающее положительные результаты общения, обучения в школе, социализации. В связи с этим достижение эмоционального благополучия детьми в условиях учреждения дошкольного образования рассматривается как важная педагогическая задача. Ее решение связано с повышением ценностного статуса детства в современном обществе, с созданием новых форм и видов развивающей среды, способной мотивировать детей, с расширением инновационных программ профессиональной подготовки педагогов. На фоне таких изменений в дошкольном образовании проблема эмоционального благополучия детей особенно значима и актуальна.

Анализ исследований и публикаций по излагаемой проблеме. Детское благополучие ученые стали изучать сравнительно недавно, однако в психологопедагогической литературе уже раскрыты многие аспекты данной проблемы. В настоящее время понятие «эмоциональное благополучие» приобрело самостоятельный статус, дифференцируюсь от более общих понятий «психическое здоровье», «психологическое здоровье», «психологическое благополучие». Вместе с тем, необходимо отметить отсутствие в психологопедагогических исследованиях единой и целостной концепции эмоционального благополучия. В большинстве случаев внимание исследователей привлекает изучение поведенческих и эмоциональных состояний детей, функций, выполняемых ими. В данном случае эмоциональное благополучие определяется 
ISSN 2077-1827. Гуманізація навчально-виховного процесу. 2020, №. 1 (99)

РОЗДІЛ. ДОШКІЛЬНЕ ВИХОВАННЯ

как показатель успешности эмоциональной регуляции социального поведения детей. Так, М. И. Лисина под эмоциональным благополучием понимает устойчивое эмоционально-положительное самочувствие ребенка, основой которого является удовлетворение основных возрастных потребностей: как биологических, так и социальных [9]. А. Д. Кошелева определяет эмоциональное благополучие как устойчиво-положительное, комфортно-эмоциональное состояние ребенка, являющееся основой отношения к миру и влияющее на особенности переживаний, познавательную, эмоционально-волевую сферу, стиль переживания стрессовых ситуаций, отношения со сверстниками [8]. А. Д. Кошелева, В. И. Перегуда, О. А. Шаграева эмоциональное благополучие детей характеризуют как один из вариантов эмоционального мироощущения, являющегося результатом взаимодействия субъективного самочувствия, эмоций, вызываемых близким взрослым (прежде всего матерью) и эмоций, связанных с успешностью освоения окружающего мира [14]. О. Л. Князева при характеристике эмоционального благополучия делает акцент на хорошей и быстрой адаптации ребенка, адекватности его поведения, социальноприемлемых способах самоутверждения и самовыражения, положительном эмоциональном фоне, оптимистическом настрое, способности к эмоциональному сопереживанию, доброжелательном отношении к другим людям, равномерном и своевременном развитии психических процессов [7].

Более объемное представление об эмоциональном благополучии детей получено исследователями за счет рассмотрения его как неотъемлемой и составной части психологического благополучия личности в целом. Эмоциональное благополучие выступает здесь интегральной характеристикой (интегральное переживание), в которой сфокусировались чувства, обусловленные успешным (или неуспешным) функционированием всех сторон личности. Эмоциональное благополучие связывается с преобладанием стабильно позитивного настроения, переживанием успешности деятельности, внимательным отношением со стороны окружающих, отсутствием переживания опасности, наличием друзей, хорошим отношением педагогов и всех окружающих $[4,5,6]$.

В настоящее время выделяется новое направление в исследовании эмоционального благополучия детей, где оно рассматривается как синоним понятия «эмоциональное здоровье». Критериями эмоционального здоровья ребенка выступают: наличие целостного эмоционального отношения к себе и к миру; способность трансформировать отрицательные эмоции и вызывать положительно окрашенные переживания; включенность во взаимодействие с социальной средой; способность к саморегуляции и творческому освоению способов, нарушающих эмоциональное благополучие $[11,12]$.

Таким образом, несмотря на разность подходов в определении эмоционального благополучия исследователи различных специальностей пришли к выводу, что оно представляет собой многомерное явление, которое определяет эмоциональное самочувствие ребенка, является показателем успешности его эмоциональной регуляции и неразрывно связано с его психологическим здоровьем. Переживая ту или иную ситуацию, то или иное отношение к себе, ребенок наделяет свое эмоциональное состояние ощущаемым чувственным смыслом, которое, без внимания педагога, может сложиться в устойчивую личностную черту - тревожность как проявление эмоционального неблагополучия. 
ISSN 2077-1827. Гуманізація навчально-виховного процесу. 2020, №. 1 (99)

РОЗДІЛ. ДОШКІЛЬНЕ ВИХОВАННЯ

В структуре эмоционального благополучия выделяется ряд компонентов, оказывающих влияние на все стороны личности ребенка, его познавательное развитие, эмоционально-волевую сферу, полноценное нравственное развитие. Такими компонентами могут явиться: эмоция удовольствия-неудовольствия как содержание преимущественного фона настроения; переживание комфорта как отсутствия внешней угрозы и физического дискомфорта; переживание успеханеуспеха в достижении целей; переживание комфорта в присутствии других людей и ситуациях взаимодействия с ними; переживание оценки другими людьми результатов своей деятельности [13]. Способность педагога оценивать эмоциональную жизнь детей, создать принимающую, поддерживающую среду для каждого воспитанника, владение вербальными и невербальными средствами общения, определенный уровень развития личностный качеств составляют основу педагогического взаимодействия, формирующего эмоциональное благополучие воспитанников. Достижение эмоционального благополучия в дошкольном возрасте обеспечивается также единством педагогических условий, которые реализуются в конкретном учреждении дошкольного образования исходя из возможностей образовательной среды, готовности всех субъектов педагогического взаимодействия. $\mathrm{K}$ общим условиям, обеспечивающим положительные эмоции у детей, ученые относят: проведение педагогической диагностики эмоциональной сферы ребенка, его эмоционального состояния, уровня эмоционального благополучия; использование форм и методов работы по развитию эмоциональной и коммуникативной сферы воспитанников, обеспечивающих развитие социально-коммуникативных навыков, эмоционально положительного опыта общения, навыков эмоционального самовыражения и эмоциональной саморегуляции; развитие уверенности в себе; коррекцию негативных эмоциональных состояний, путем использования игровых технологий, направленных на развитие личности ребенка как субъекта образовательной деятельности [3, 8].

Изучая эмоциональные проявления детей, исследователи обнаружили, что любая деятельность является для ребенка полимотивированной, т.е. побуждаемой разными мотивами, и, во-вторых, полиэмоциональной, т.е. вызывающей разные и по динамике, и по содержанию эмоциональные явления [8]. В нашем исследовании достижение эмоционального благополучия воспитанниками зависело от грамотно построенных структур двигательной деятельности в учреждении дошкольного образования, а также специально используемых средств физического воспитания. Общеизвестно, что движения имеют важную характеристику - выразительность [2]. С помощью выразительности движений активизируются моторные механизмы эмоционального отклика, опосредованно приводится в действие эмоциональная сфера в целом. Кроме того, выразительные движения дают возможность сбалансировать моторные механизмы эмоциональных проявлений, снимая психологическое напряжение. Психологи, рассматривая тоническую функцию движений, называют их «экстериоризированными эмоциями» и отмечают, что движения являются экспрессивным средством выражения человеком собственных переживаний [1]. Эти научные положения легли в основу нашей экспериментальной работы.

Формулирование целей статьи. Цель статьи - изучение теоретических подходов к проблеме эмоционального благополучия детей, исследование роли двигательно-игровой деятельности как средства эмоционального развития детей дошкольного возраста. 
ISSN 2077-1827. Гуманізація навчально-виховного процесу. 2020, №. 1 (99)

РОЗДІЛ. ДОШКІЛЬНЕ ВИХОВАННЯ

Изложение основного материала исследования с полным
обоснованием полученных научных результатов. Исследование проводилось
на базе государственного учреждения образования «Ясли-сад № 551 г. Минска»
(72 ребенка - экспериментальная группа) и государственного учреждения
образования «Ясли-сад № 412 г. Минска» (70 детей - контрольная группа).
Целью исследования явилось опытно-экспериментальное изучение эмоционального благополучия детей старшего дошкольного возраста, выявление как положительных, так и отрицательных сторон изучаемой проблемы; определение содержания педагогической деятельности, направленной на формирование у воспитанников позитивных эмоций, позитивного отношения к себе в процессе выполнения физических упражнений.

В констатирующей части эксперимента изучению подвергались два показателя эмоционального благополучия детей: положительный фон настроения, эмоциональное благополучие ребенка в двигательной деятельности. В диагностике изучаемых показателей использовалась следующая система оценки: «достаточная степень проявления показателя», «степень проявления близкая к достаточной», «недостаточная степень проявления изучаемого показателя». Выявлению положительного фона настроения, удовлетворения ребенка собой способствовала методика «Автопортрет» [10]. С помощью данной методики ребенок в рисунке показывал, какой он есть сегодня и каким хочет стать в будущем. Сформированная проекция личностной составляющей, проявляющаяся в рисунке, давала возможность для анализа достоинств и конструктивных потенций детей, а также способствовала выявлению нарушений в их эмоциональной сфере. Анализ материалов исследования показал, что воспитанники, отнесенные к достаточной степени проявления положительного фона настроения, вполне удовлетворены собой. Это подтверждалось их положительным отношением к себе, внутренней гармонией, способностью к самопознанию и саморегуляции. Дети предвидели перспективы изменения себя, адекватно оценивали свои возможности, при этом вполне были ими довольны. В рисунках наблюдались различия в представлении себя «Я, какой есть» и «Я, каким хочу стать» в сторону большей идеализации последнего. Это говорит о том, что дети хотят стать лучше и знают, как этого добиться, имеют жизнерадостное, бодрое настроение, оптимистичный настрой. Данную степень проявления изучаемого показателя в исследовании обнаружило 17,9 \% детей экспериментальных и 20,7 \% детей контрольных групп. Положительный фон настроения близкий к достаточному был зафиксирован у 43,3 \% детей экспериментальных и 42,9 \% детей контрольных групп. Эти дети также отличались удовлетворенностью собой. Однако в проекциях себя в рисунке они не стремились что-то менять в себе. «Реальное Я» было изображено крупнее, ярче, выразительнее, чем «Я идеальное». Способность к самопознанию, стремление к идеалу, развитию и взрослению у детей были слабо выражены. Это свидетельствует об отсутствии представлений ребенка о себе в будущем. Дети, имеющие недостаточную степенью проявления положительного фона настроения (38,8 \% детей экспериментальных групп и 36,4 \% детей контрольных групп), характеризовались общим безразличием к себе. Изображение человека в рисунках детей было деформировано, непропорционально, ущербно («конфликтно»). Например, на руке отсутствовали пальцы, пропорции тела были искажены, наблюдалась утолщенность линий. Все это говорит об эмоциональном неприятия ребенком себя. Наблюдались трудности в 
ISSN 2077-1827. Гуманізація навчально-виховного процесу. 2020, №. 1 (99)

РОЗДІЛ. ДОШКІЛЬНЕ ВИХОВАННЯ

представлении ребенком себя в будущем. В рисунках отсутствовала способность к самопознанию, стремление к идеалу, развитию, взрослению. Детей характеризовало также неустойчивое, переменчивое настроение, раздражительность, что означало наличие актуальных для ребенка конфликтов и личностных проблем.

Эмоциональное состояние детей в двигательной деятельности оценивалось с помощью методики «Мое настроение на занятии физическими упражнениями» (модифицированный метод диагностики эмоционального состояния ребенка, автор О.А. Орехова). Ребенку предлагалась бумага и цветные карандаши, давалась инструкция: «Закрой глаза, представь, что ты сейчас в физкультурном зале. Вместе с детьми ты выполняешь разные виды физических упражнений на физкультурном занятии. Какое у тебя настроение веселое или грустное?» Затем ребенок открывал глаза и, не называя цвета, находил подходящий по цвету карандаш, делал им любую отметку на бумаге. После этого обсуждались следующие компоненты двигательного режима утренняя гимнастика, подвижные игры и физические упражнения на прогулке. Результаты анализа материалов исследования показали, что большинство детей испытывали эмоциональное благополучие в двигательной деятельности $(58,1 \%$ детей экспериментальных групп и 59,0 \% детей контрольных групп). При выполнении экспериментальных заданий они выбирали соответствующие цвета карандашей (красный, желтый, зеленый), характеризующие эмоциональное благополучие. Однако также было зафиксировано, что у 41,9\% детей экспериментальных групп и у 41,0 \% детей контрольных групп настроение во время занятий физическими упражнениями не было положительным, дети выбирали цвета, проецирующие эмоциональное неблагополучие (синий, фиолетовый, коричневый, черный).

Результаты итогового анализа материалов диагностических методик позволили констатировать, что степень проявления основных признаков эмоционального благополучия детей контрольных и экспериментальных групп зафиксирована как недостаточная. В экспериментальных группах оптимальная степень эмоционального благополучия обнаружена у 17,2\% испытуемых, допустимая у 27,6\%, недопустимая у 55,2\%. Эмпирические данные фактически идентичны полученным результатам по каждому из показателей изучаемого компонента между экспериментальными и контрольными группами.

В формирующей части эксперимента использовались формы и методы работы, обеспечивающие навыки эмоционального самовыражения ребенка в двигательной деятельности, влияющие на осознание им своих чувств, переживаний и эмоциональных состояний. Главным условием реализации поставленной цели выступала игра. Учеными доказано, что в игре, с одной стороны, обнаруживаются уже сложившиеся у детей способы и привычки эмоционального реагирования, с другой, - формируются новые качества поведения, развивается и обогащается эмоциональный опыт. Особо значим в игре момент перевоплощения в игровой образ, он выступает важнейшим условием перестройки и оптимизации эмоциональной сферы детей. Действуя в воображаемой ситуации за другого, ребенок присваивает черты другого и испытывает чувства другого, свои чувства, мешавшие ему в жизни, при этом отодвигаются на второй план. Двойное самочувствие ребенка в игре обогащает его эмоциональную сферу, способствует пониманию им скрытого смысла ситуации, приводит к формированию новых положительных качеств, новых 
ISSN 2077-1827. Гуманізація навчально-виховного процесу. 2020, №. 1 (99)

РОЗДІЛ. ДОШКІЛЬНЕ ВИХОВАННЯ

побуждений и потребностей [15]. Учитывая данные положения, мы разработали сценарии игровых физкультурных занятий (двигательные инсценировки), в которых дети с помощью средств образной выразительности (мимики, жеста, позы, походки и т.п.) разыгрывали двигательный образ. Двигательные инсценировки строились на знакомых детям простых жизненных ситуациях, сюжетах народных сказок, детских литературных произведений. Создание образов с помощью движений вызывало у воспитанников эмоциональное отношение к двигательной деятельности, вовлекало в мыслительный процесс такие качества, как сообразительность, гибкость, способность переносить свойства выполняемого движения на новый игровой образ. В результате неоднократного использования одних и тех же способов выполнения движений в разных ситуациях дети приходили к их обобщению, что делало движение осознанным. Двигательные инсценировки способствовали образному перевоплощению исполнителей, их общению между собой в соответствии с сюжетным развитием, давали возможность достигать успеха. Гордость ребенка за личные достижения повышала его инициативу в овладении выполняемой деятельностью, расширяла возможности вступления в контакт с педагогом и детьми, обеспечивала более благоприятное положение среди сверстников, способствовала формированию навыков эмоциональной саморегуляции, умению объяснять свои действия, находить и исправлять ошибки.

Эффективность влияния физических упражнений на эмоциональное состояние детей увеличивалась, когда они использовались в комплексе с другими способами эмоциональной саморегуляции. Одним из таких способов явился прием воображения или визуализации. Визуализация - это создание внутренних образов в сознании ребенка, т.е. активизация воображения с помощью слуховых, зрительных, вкусовых, обонятельных, осязательных ощущений, а также их комбинаций. В исследовании прием визуализации сопровождался выполнением детьми физических упражнений с ритмическим музыкальным сопровождением. Использование музыки подсказывало ребенку характер движения, помогало выполнять его без строгого контроля и регламентации, положительно сказывалось на настроении и самочувствии, помогало справиться со стрессами. Уменьшить эмоциональное напряжение, ослабить или прекратить отрицательные эмоции, обрести спокойствие помогали также специально подобранные дыхательные упражнения. Они имели игровую форму проведения и вызывали у детей раскованность в поведении, положительный эмоциональный настрой.

Таким образом, игровая форма организации двигательной деятельности, обеспечивающей преобладание положительных эмоций, понимание ребенком характера переживаемых эмоций, приобретение эмоционально положительного опыта общения со сверстниками может явиться действенным фактором формирования эмоционального благополучия детей.

Выводы. Теоретическим основанием изучения эмоционального благополучия детей дошкольного возраста являются положения психологопедагогической науки об эмоциональном благополучии как составной части психологического здоровья. Эмоциональное благополучие связано с переживанием ребенком положительного или отрицательного опыта отношений, общения и деятельности. Это проявляется на уровне переживания удовольствия - неудовольствия; успеха - неуспеха; комфорта - дискомфорта; положительнойотрицательной оценки результатов активности ребенка окружающими. 
ISSN 2077-1827. Гуманізація навчально-виховного процесу. 2020, №. 1 (99)

РОЗДІЛ. ДОШКІЛЬНЕ ВИХОВАННЯ

Успешность достижения эмоционального благополучия в условиях занятия физическими упражнениями неразрывно определяется использованием систематизированных игровых технологий, обеспечивающих эмоциональное развитие детей.

\section{СПИСОК ИСПОЛЬЗУЕМОЙ ЛИТЕРАТУРЫ}

1. Аболин А. М. Психологические механизмы эмоциональной устойчивости человека. Казань: КГУ, 1987. 262 с.

2. Бернштейн Н. А. Очерки по физиологии движений и физиологии активности. Москва.: Медицина, 1966. 347 с.

3. Бадулина О. И. Педагогические основы эмоционального благополучия дошкольников: дис. канд. пед. наук. Москва., 1998. 125 с.

4. Дубровина И. В. Психическое и психологическое здоровье в контексте психологической культуры личности. Вестник практической психологии образования. 2010. № 3. 17-21 с.

5. Ежкова Н. С. Дошкольный возраст: образование с учетом эмоционального компонента. Дошк. воспитание. 2004. № 8. 65-70 с.

6. Запорожец А.В. Взаимосвязь развития когнитивных и эмоциональных процессов у ребенка. Вопр. психологии. 1974. № $6.74-75$ с.

7. Князева О. Л. Я-Ты-Мы: Программа социально-эмоционального развития дошкольников. Москва: Мозаика-Синтез. 2005. 166 с.

8. Кошелева А. Д. Эмоциональное развитие дошкольников. Москва. Академия, 2003. $176 \mathrm{c.}$

9. Лисина М. И. Формирование личности ребенка в общении. СанктПетербург.: Питер, 2009. 320 с.

10. Орехова О. А. Цветовая диагностика эмоций человека. Санкт-Петербург.: Речь, 2002. 108 с.

11. Семенова Е. М. Психологическое здоровье ребенка и педагога: пособие для педагогов учреждений, обеспечивающих получение дошкольного образования. Мозырь: Белый ветер, 2010. 174 с.

12. Тарабакина Л. В. Эмоциональное здоровье как предмет социальнопсихологического исследования. Теория и практика общественного развития. 2015. № 8. 48-56 с.

13. Филиппова Г. Г. Эмоциональное благополучие ребёнка и его изучение в психологии. Детский практический психолог: Программьи и методические материаль: учеб. пособие для студентов высших пед, учебных заведений. Москва: Просвещение. 2001. 356 с.

14.Эмоциональное развитие дошкольников: учебное пособие / А. Д. Кошелева, В. И. Перегуда, О. А. Шаграева, С. А. Козлова. Москва: Академия. 2003. 169 с.

15. Эльконин Д. Б. Избранные психологические труды. Москва.: Педагогика. 1989. $560 \mathrm{c}$.

Стаття надійшла до редакції 25.12.2019.

\section{ШЕБЕКО Валентина}

доктор пед. наук, доцент, професор кафедри методик дошкільної освіти закладу освіти «Білоруський державний педагогічний університет імені Максима Танка»

вул. Радянська, 18, Минск, Беларусь, 220050, Мінськ, Білорусь, 220117 
ISSN 2077-1827. Гуманізація навчально-виховного процесу. 2020, №. 1 (99)

РОЗДІЛ. ДОШКІЛЬНЕ ВИХОВАННЯ

E-mail: walj-schebeko@mail.ru

ГО Ке

аспірант кафедри методик дошкільної освіти закладу освіти «Білоруський державний педагогічний університет імені Максима Танка»

вул. Радянська, 18, Минск, Беларусь, 220050,

E-mail: 302900817@qq.com

\section{ЕМОЦЙНЕ БЛАГОПОЛУЧЧЯ ДОШКІЛЬНОГО ВІКУ, ПРОБЛЕМА ФОРМУВАННЯ \\ \begin{tabular}{ll} 
ДІТЕЙ & \multicolumn{1}{c}{ СТАРШОГО } \\
ИОГО ВИВЧЕННЯ I
\end{tabular}}

Анотація. У статті представлено аналітичний огляд теоретичних підходів до проблеми емоційного благополуччя дітей. Відзначається, що поняття «емоційне благополуччя» придбало самостійний статус, диференціюючись від більш загальних понять «психічне здоров'я», «психологічне здоров'я», «психологічне благополуччя». Увагу дослідників привертає вивчення поведінкових і емоційних станів дітей, функцій, виконуваних ними. В даний час виділяється новий напрямок в дослідженні емоційного благополуччя дітей, де воно розглядається як синонім поняття «емоційне здоров'я», критеріями якого виступають: наявність цілісного емоційного ставлення дитини до себе і до світу; здатність трансформувати негативні емоції й викликати позитивно забарвлені переживання; включеність у взаємодію з соціальним середовищем; здатність до саморегуляції й творчого освоєння способів, що порушують емоційне благополуччя. Незважаючи на різницю підходів у визначенні емоційного благополуччя, дослідники різних спеціальностей дішли висновку, що воно являє собою багатовимірне явище, яке визначає емоційне самопочуття дитини, $\epsilon$ показником успішності іiі емоційної регуляції й нерозривно пов'язане 3 його психологічним здоров'ям.

Метою дослідження було дослідно-експериментальне вивчення емоційного благополуччя дітей старшого дошкільного віку, виявлення як позитивних, так і негативних сторін досліджуваної проблеми; визначення змісту педагогічної діяльності, спрямованої на формування у вихованців позитивних емоцій, позитивного ставлення до себе в процесі виконання фізичних вправ.

Наводяться дані емпіричного дослідження стану емоційного благополуччя дітей старшого дошкільного віку. Результати підсумкового аналізу матеріалів діагностичних методик дозволили констатувати, що прояв суттєвих ознак емоційного благополуччя дітей контрольних та експериментальних груп зафіксована як недостатній. У формувальній частини експерименту використовувалися форми i методи роботи, що забезпечують навички емоційного самовираження дитини в руховій діяльності, що впливають на усвідомлення нею своїх почуттів, переживань й емоційних станів. Головною умовою реалізації поставленої мети виступала гра.

Дослідженням доведено, що в грі, 3 одного боку, виявляються вже сформовані у дітей способи і звички емоційного реагування, 3 іншого, формуються нові якості поведінки, розвивається й збагачується емоційний досвід. Особливо значущий в грі момент - перевтілення в ігровий образ, він виступає найважливішою умовою перебудови і оптимізації емоційної сфери дітей. Таким чином, ігрова форма організації рухової діяльності, що забезпечує переважання позитивних емоцій, розуміння дитиною характеру пережитих емоцій, придбання емоційно позитивного досвіду спілкування 3 однолітками може бути дієвим фактором формування емоційного благополуччя дітей. 
ISSN 2077-1827. Гуманізація навчально-виховного процесу. 2020, №. 1 (99)

РОЗДІЛ. ДОШКІЛЬНЕ ВИХОВАННЯ

Ключові слова: психологічне здоров'я, емоційне благополуччя, емоційний розвиток, позитивний фон настрою, рухова діяльність, гра, рухові інсценування, музично-ритмічні вправи.

\section{SHEBEKO Valentina}

$\mathrm{PhD}$ in Pedagogical Sciences, Associate Professor, Professor of the Department of Teaching Methods of Preschool Education, the Educational Institution "Belarusian State Pedagogical University named after Maxim Tank"

18 Sovetskaya Street, Minsk, Belarus, 220050

E-mail: walj-schebeko@mail.ru

GUO Ke

Postgraduate Student of the Department of Teaching Methods of Preschool Education, the Educational Institution "Belarusian State Pedagogical University named after Maxim Tank"

18 Sovetskaya Street, Minsk, Belarus, 220050

E-mail: 302900817@qq.com

RESEA RCH AND FORMATION OF EMOTIONAL WELL-BEING OF CHILDREN OF PRESCHOOL AGE

Summary. The article presents the analytical overview of the theoretical approaches to the problem of emotional well-being of children. The main indicators of emotional well-being and the criteria that can be used to improve the quality of life of pupils are considered. The empirical study of the state of emotional well-being of children with preschool age is represented. The role of motor-game activity as a means of expressing feelings and emotional development of children is shown.

Keywords: psychological health, emotional welfare, emotional development, positive mood, motor activity, game, motor dramatization, musical rhythmic exercises.

Abstract. Introduction. The relevance of the problem of emotional well-being of preschool children is determined by the social order of the society to bring up a healthy child, therefore, the preschool period of childhood should be permeated with concern for the physical health and mental well-being of pupils. The emotional wellbeing of children is considered as an indicator of the optimality of general mental development, which determines the positive attitude of the child to the world and to himself/herself, providing positive results of communication, learning at school, and socialization.

Analysis of publications. The theoretical foundations of the problem of the formation of emotional well-being of preschool children have been studied in the works of O. I. Badulina, M. I. Lisina, A. D. Kosheleva, V. I. Pereguda, G. G. Filippova, O. A. Shagraeva, and others. In most cases, the attention of researchers is drawn to the study of the behavioural and emotional states of children, the functions performed by them. The emotional well-being is defined as an indicator of the success of the emotional regulation of children's social behaviour. Currently, a new direction is being highlighted in the study of children's emotional well-being, where it is regarded as a synonym for the concept of "emotional health".

Purpose. The purpose of the article is to study the theoretical approaches to the problem of the emotional well-being, to investigate the role of the motor-game activity as a means of emotional development of preschoolers.

Results. The concept of "emotional well-being" has acquired an independent status, differentiating itself from the more general concepts of "mental health", "psychological health", and "psychological well-being". In most cases, the attention of researchers is drawn to the study of the behavioural and emotional states of children, 
and the functions performed by them. In the given case, the emotional well-being is defined as an indicator of the success of the emotional regulation of children's social behaviour. Currently, a new direction is being highlighted in the study of children's emotional well-being, where it is regarded as a synonym for the concept of "emotional health", the criteria of which are: the presence of a holistic emotional relationship of the child to himself/herself and to the world; the ability to transform negative emotions and evoke positively coloured experiences; the involvement in interaction with the social environment; the ability to self-regulation and creative development of ways that violate emotional well-being. Despite the difference in approaches in determining the emotional well-being, researchers of various specialities have come to the conclusion that it is a multidimensional phenomenon that determines the emotional well-being of a child, is an indicator of the success of his/her emotional regulation and is inextricably linked to his/her psychological health.

The purpose of the study was an experimental study of the emotional wellbeing of children of preschool age, the identification of both positive and negative aspects of the problem under study; the determination of the content of pedagogical activity aimed at forming pupils' positive, their positive attitude towards themselves in the process of performing physical exercises.

The data of the empirical study of the state of the emotional well-being of children of preschool age are given. The results of the final analysis of the materials of diagnostic techniques allow stating that the degree of manifestation of the main signs of the children's emotional well-being in the control and experimental groups is recorded as insufficient. In the forming part of the experiment, the forms and working methods were used that provide the child with emotional self-expression skills in motor activity, which affect his/her awareness of his/her feelings, experiences and emotional states. The main condition for the realization of the purpose set was the game.

The study proves that in the game, on the one hand, children's already developed ways and habits of emotional response are detected, on the other hand, new qualities of behaviour are formed, emotional experience develops and enriches. Particularly significant in the game, it is the moment of transformation in a game image, it is the most important condition for the restructuring and optimization of the children's emotional sphere.

Conclusion. Thus, the game form of organizing the motor activity, which ensures the predominance of positive emotions, the child's understanding of the nature of the emotions experienced, the acquisition of emotionally positive experience with peers, can be an effective factor in the formation of children's emotional well-being.

\section{REFERENCES}

1. Abolin, A. M. (1987). Psikhologicheskie mekhanizmy emotcionalnoi ustoichivosti cheloveka [Psychological mechanisms of human emotional stability]. Kazan: KGU [in Russian].

2. Bernshtein, N. A. (1966). Ocherki po fiziologii dvizhenii i fiziologii aktivnosti [Essays on physiology of movements and physiology of activity]. M.: Meditcina [in Russian].

3. Badulina, O. I. (1998). Pedagogicheskie osnovy emotcionalnogo blagopoluchiia doshkolnikov [Psychological fundamentals of preschoolers' emotional wellbeing]. Candidate's thesis. Moskva [in Russian]. 
ISSN 2077-1827. Гуманізація навчально-виховного процесу. 2020, №. 1 (99)

РОЗДІЛ. ДОШКІЛЬНЕ ВИХОВАННЯ

4. Dubrovina, I. V. (2010). Psikhicheskoe i psikhologicheskoe zdorove v kontekste psikhologicheskoi kultury lichnosti [Mental and psychological health in the context of the personality's psychological culture]. Vestnik prakticheskoi psikhologii obrazovaniia - Bulletin of Practical Psychology of Education, 3, 17-21 [in Russian].

5. Ezhkova, N. S. (2004). Doshkolnyi vozrast: obrazovanie s uchetom emotcionalnogo komponenta [Preschool age: education taking into account the emotional component]. Doshk. Vospitanie - Preschool Upbringing, 8, 65-70 [in Russian].

6. Zaporozhets, A. V. (1974). Vzaimosviaz razvitiia kognitivnykh i emotcionalnykh protcessov $\mathrm{u}$ rebenka [Interconnection of development of cognitive and emotional processes in the child]. Vopr. Psikhologii - Issues of Psychology, 6, 74-75 [in Russian].

7. Kniazeva, O. L. (2005). Ia-Ty-My: Programma sotsialno-emotcionalnogo razvitiia doshkolnikov [I-You-We: Programme of social-economic development of preschoolers]. M.: Mozaika-Sintez, Domodedovo: DPK [in Russian].

8. Kosheleva, A. D. (2003). Emotsionalnoe razvitie doshkolnikov [The child's emotional development]. M.: Akademiia [in Russian].

9. Lisina, M. I. (2009). Formirovanie lichnosti rebenka v obshchenii [Forming the child's personality when communicating]. Spb.: Piter [in Russian].

10. Orekhova, O. A. (2002). Tsvetovaia diagnostika emotcii cheloveka [Colour diagnostics of man's emotions]. Spb.: Rech [in Russian].

11. Semenova, E. M., \& Chesnokova, E. P. (2010). Psikhologicheskoe zdorove rebenka $i$ pedagoga: posobie dlia pedagogov uchrezhdenii, obespechivaiushchikh poluchenie doshkolnogo obrazovaniia [The child's and educator's psychological health: manual for educators of institutions which provide receiving preschool education]. E. A. Panko (Ed.). Mozyr: Belyi veter [in Russian].

12. Tarabakina, L. V. (2015). Emotcionalnoe zdorove kak predmet sotcialnopsikhologicheskogo issledovaniia [Emotional health as a subject of socio=psychological studying]. Teoriia $i$ praktika obshchestvennogo razvitiia Theory and Practice of Social Development, 8, 48-56 [in Russian].

13. Filippova, G. G. (2001). Emotcionalnoe blagopoluchie rebenka i ego izuchenie v psikhologii [The child's emotional well-being and learning it in psychology]. Detskii prakticheskii psikholog: Programmy i metodicheskie materialy: ucheb. posobie dlia studentov vysshikh ped, uchebnykh zavedenii - Children's Practical Psychologist: Programmes and Methodic Materials: manual for students of higher pedagogical educational institutions. O. A. Shagraeva, S. A. Kozlova (Eds.). M.: Prosveshchenie [in Russian].

14. Kosheleva, A. D., Pereguda, V. I., Shagraeva, O. A., \& Kozlova, S. A. (2003). Emotcionalnoe razvitie doshkolnikov: uchebnoe posobie [Preschoolers' emotional development: teaching guide]. Moskva: Akademiia [in Russian].

15. Elkonin, D. B. (1989). Izbrannye psikhologicheskie Trudy [Selected psychological works]. V. V. Davydova, V. P. Zinchenko (Eds.). M.: Pedagogika [in Russian].

(перевод на англ. язік Го Кэ - аспирант кафедры методик дошкольного образования учреждения образования «Белорусский государственный педагогический университет имени Максима Танка») 